list of seventy-nine disabilities treated in that way, and included we find three cases of suppuration after enucleation of the eye, and one case of suppuration in the lacrymal sac. As regards the first-named condition, the ozone appears to have acted well and promptly; but in the last-named no result was noted after twenty-one applications, and the sac was eventually removed.

\title{
Cutaneous Reactions
}

An interesting paragraph in the April number of American Medicine deals with the effect of the administration of certain drugs upon the different skin reactions. From recent researches it appears that normal individuals react positively to the luetin test after the administration of sixty or more grains of potassium iodide. Tuberculin reactions are intensified after iodides or bromides have been given. It is clearly of importance to distinguish between skin reactions of specific origin and those due to the administration of drugs. Indeed, it is by no means unlikely that failure to recognize the influence of medicines ingested may account in part for the divergent results obtained by observers with the luetin reaction and similar diagnostic tests.

\section{ABSTRACTS}

\section{I.-GUMMATA}

(1) Werner, F. (Jena).-Symmetrical gumma formation in the orbits. (Ueber symmetrische Gummibildung der Orbita.) Klin. Monatsbl.f. Augenheilk., March-April, I9I4.

(2) Pissarello, C.-A case of ulcerating gumma of the lid due to late hereditary syphilis. (Sopra un caso di gomma ulcerata delle palpebre, manifestazione sifilitica ereditaria tardiva.) Arch. di Ottalm., July, 1916.

(1) Werner reports the following case:-A healthy married woman, fifty years of age, complained of a left-sided headache of fourteen days' duration. There was redness and swelling of the lower lid, towards the external canthus, but no tenderness. A small tumour, about the size of a bean, could be felt on the outer end of the lower orbital margin. It was believed to be fibro-sarcoma, and was excised. A year later the patient returned with a similar tumour in the right orbit. Meanwhile the original growth had been found to be a granulation tumour, and a positive Wassermann reaction had been obtained. Gumma was therefore suspected, and, under salvarsan treatment, the new growth disappeared. The case serves to remind 
us of the possibility that an orbital tumour may be of chronic inflammatory origin, and that this should be excluded before operation.

A. J. Ballantyne.

(2) Pissarello records a case of this rare affection in a man of 22 years. Acquired syphilis could be excluded. There was a history of some skin disease in infancy, and five years before he came under Pissarello's care, he had suffered from a perforation of the palate, which had been successfully operated on. The affection of the eye had been first noticed some five months previously, as a swelling with redness, which involved both eyelids of the right eye. When first seen, the lids were greatly swollen, and a large and deep ulcer occupied the region of the internal angle and the inner-third of the upper lid and two-thirds of the lower. The edges were sharply cut and raised, and the base covered by a greyish membrane, which was easily removable. The eye was unaffected, and the vision normal. The submaxillary, preauricular, and cervical glands were painlessly enlarged. He had ozæna, a depressed nose bridge, and teeth indicative of hereditary syphilis. Microscopical examination of the scrapings from the ulcer showed neither tubercle bacilli nor spirochætes. Intradermal tubercle reaction was negative; Wassermann strongly positive. Intensive treatment with mercury and iodide was successful in curing the condition.

Pissarello goes on to discuss the difficulties of the differential diagnosis of these cases, and appends a bibliography. An illustration of the condition before and after treatment accompanies the paper.

E. E. H.

\section{II.-OCULAR TUBERCULOSIS}

(I) Otori (Japan).-Pathological and experimental investigations on primary tuberculosis of the retina. (Pathologischanatomische und experimentelle Untersuchungen zur Kenntnis der primaren Netzhauttuberkulose.) Arch. $f$. Augenheilk., Bd. LXXIX, Heft ii and iii, S. 44.

(2) McCool, Joseph L. (Portland).-Some observations on ocular tuberculosis and its treatment. Ophthal. Rec., January, I9ı6.

(3) Posey, W. Campbell (Philadelphia). - A consideration of some of the ocular conditions dependent upon tuberculosis and systemic gonorrhœa. Ophthal. Rec., January, Ig16.

(4) Gamble, W. E. (Chicago).- Tuberculosis of the eye, with special reference to treatment. Ophthal. Rec., February, I9I6.

(1) Of cases of primary tuberculosis of the retina, Otori has found in the literature three : one by O'Sullivan and Story, one by Hancock, and one by Komoto. There are also five cases of tuberculosis of 
the optic nerve reported by Sattler, Verderame, Knapp, Jacobs, and Komoto. Synopses of these are given.

Otori's personal cases are as follows :-

CASE I.-S. G., barber, 23 years. Parents dead, no hereditary taint. Four years previously ill with pleurisy and pneumonia, followed by lung hæmorrhage. In April, 1912, hæmoptysis, spots before the left eye, followed by diminution in vision. For some days spots before right eye. The left eye is painful.

Present condition.-A slim man, well developed. No glandular swelling. Left eye slightly divergent, slight conjunctival and ciliary injection, especially at the temporal side. Cornea clear, anterior chamber shallow, aqueous slightly cloudy, pupil (under atropine) moderately dilated, many posterior synechiæ, iris discoloured, fundus cloudy. V. Hand-movements at 1/2 metre. R.V. 6/6.

July 20.-Severe pain in left eye.

July 26.-Cornea has a diffuse grey opacity. Aceto-salicylic acid without effect.

August 15.-Paracentesis; slight hæmorrhage from iris.

August 17.-Enucleation.

The eyeball was fixed in Zenker's solution, embedded in celloidin, and cut in serial section.

The microscopic appearance of the cornea, sclera, itis, ciliary body, lens, choroid, and retina is given in detail. Evidence of tubercle bacilli in retina: it is very difficult in primary tuberculosis of the retina to demonstrate the tubercle bacillus. Up to the present this has only been done by Knapp and Verderame in cases of tuberculosis of the optic nerve. All attempts at demonstration in retinal tissue have, up to the present cases, been negative.

Otori's preparations were stained by a modified method.-2-4 hours with hot carbol-fuchsin, then a very short time in 0.5 per cent. hydrochloric acid alcohol with tincture of iodine, and washed off with distilled water, then differentiated a number of times in picric acid solution with indigo-carmine.

It is to be noted that the bacilli were demonstrated in the equatorial region. They were especially numerous in round-celled accumulations about the peripheral veins. They were not found in the uveal tract.

CASE II.-A woman, 51 years old, who on May 17, 1912, came to the clinic with a severe plastic iritis of the left eye, coincident with influenza. Hæmorrhages in the anterior chamber and vitreous.

On the fifth of the next month, an iridectomy was performed and on June 12 the eye was enucleated, on account of pain.

The microscopic examination of the cornea, sclera, ciliary body, lens, choroid, retina, is given. Staining for tubercle bacilli was carried out as in the first case. Everywhere in the retina tubercle bacilli were found. They were not discovered in the choroid. 
The article closes with the results of some inoculation experiments, and is illustrated with one microphotograph and two drawings.

HANFORD MCKEE.

(2) $\mathrm{McC}$ ool refers to the protean manifestations of tuberculosis of the eye and the difficulties of diagnosis. He regards the subcutaneous injection of old tuberculin as the most trustworthy test. But a general reaction, as evidenced by a feeling of malaise and a rise of temperature, by no means determines the tuberculous nature of the ocular disease. To establish this to a certainty, it is necessary to secure a focal reaction as well, although he admits that this is not always possible, as in disease of the choroid and optic nerve. In the absence of a focal reaction in ocular inflammation of obscure origin, a general and local reaction may be considered conclusive when no tubercle can be found in other parts of the body, and syphilis, gonorrhœa, accessory sinus disease, carious teeth, and infected tonsils can be excluded. In children under ten years of age, von Pirquet's cutaneous reaction is fairly trustworthy.

The writer does not definitely state the dose of O.T. given for diagnostic purposes, but in one case of choroiditis and hyalitis $0.5 \mathrm{mg}$. was given subcutaneously; and although there was a marked local reaction there was no general reaction; two days later $20 \mathrm{mg}$. O.T. were given, and resulted in a severe local reaction, a general reaction, a feeling of heat in and around the eye.

In the treatment of these cases he uses, as a rule, bacillary emulsion, starting with $1 / 10,000 \mathrm{mg}$. and gradually increases the dose, trying always to avoid a reaction, eventually working up to $1 / 500 \mathrm{mg}$. and even $1 / 140 \mathrm{mg}$. The intervals between the injections vary from two or three days to a week. When using T.R. he starts with 1/2,000 mg., increasing the dose, after a week, to $1 / 1,000 \mathrm{mg}$. which is repeated weekly for three weeks, and then increased to $1 / 500 \mathrm{mg}$.

He cites the successful treatment of cases of conjunctivitis, of blepharitis and phlyctenular conjunctivitis, nodular keratitis, scleritis, and sclero-keratitis, episcleritis and scleritis, kerato-iridocyclitis and choroiditis with hyalitis-all in adults.

In all cases it is well to explain to the patient the nature of the treatment, that it is going to be slow and tedious, and that there will be exacerbations in the symptoms from time to time; but at the same time it is essential to maintain an optimistic attitude as to the end result, otherwise, "the patient will most surely become dissatisfied and discouraged and consult some one else."

J. Jämeson Evans.

(3) Posey points out the necessity for a test for ocular tuberculosis, since physical signs of that disease elsewhere in the body are so often wanting. He adopts the method of subcutaneous injection of T.O. and gives an initial dose of 1 milligramme. 
If there is no general or local reaction, a second dose of 2 milligrammes is given at the end of forty-eight hours. If this is again negative, a third dose of 3 milligrammes is administered at the end of the fourth day. Should this again be negative, it must be assumed that the process is not tuberculous, although he cites Trudeau as stating that negative results with the "moderate" (sic) doses described should not be considered infallible. Posey states, and we can quite believe him, that the general reaction which may follow these diagnostic injections is often alarming, and may lead the patient to abandon the tuberculin treatment which should follow. With regard to the von Pirquet test, while a positive reaction may be misleading, two negative vaccinations must be regarded as practically excluding a tuberculous focus.

For therapeutical purposes the author follows the method of von Hippel, with some modifications, beginning with a dose of $1 / 500$ mg. of T.R., and doubling the dose every forty-eight hours until a reaction, general or local, is obtained. "After an interval of some days, when the reaction has subsided, the dose weakest to that which produced the reaction is injected twice a week until the condition is improved, when the treatment is applied less frequently." The maximum dose so administered should not exceed $1 \mathrm{mg}$.

The author describes some of the ocular manifestations of tuberculosis, and commends the adoption of anti-tuberculous régime, in addition to the tuberculin treatment.

He gives an historical review of systemic gonorrhœa as it affects the eye, and refers particularly to the work of John Griffith and W. M. Beaumont. Vaccine and serum treatment have not been attended with success in his hands. In some cases, indeed, the administration of serum was productive of definite aggravation of symptoms.

J. JaMEson Evans.

(4) Gamble draws attention to the dangers of operative interference with tuberculous eyes, and puts in a plea for conservative measures. In the presence of glaucomatous tension which is unrelieved by miotics, he suggests trephining in preference to iridectomy. He reviews the experimental work of Roemer, Rothe and Bierbaum, Stock, and others, showing the great variations in the virulence and course of tuberculous lesions, and the marked capacity of the ocular tissues for absorbing tuberculous deposits. He refers to the very restricted value of a general tuberculin reaction, since practically the whole human race has been infected, and the mass of evidence which has accumulated to show that pronounced reactions are liable to cause general dissemination of the bacilli. The skin reaction also is of little diagnostic value, except when it is repeatedly negative.

Focal reactions, unfortunately, are rare, except after large 
diagnostic doses, although the author has seen typical focal reaction in tuberculous iritis, without general reaction, with the administration of 10/500 mg. T.R.; and Sydney Stephenson on two occasions produced both general and focal reactions in cases of chronic iridocyclitis by $1 / 1000 \mathrm{mg}$. T.R.

The author thinks that a more careful study of the suspected tuberculous area in the light of what we now recognize as a focal reaction, makes it unnecessary to use the larger doses in many cases. Stock states that "focal reaction often consists of tiny grey deposits, or thickenings of the iris in the inner circle of that membrane." It may be only hyperæmia of the vessels, or hæmorrhages about the tuberculous nodules, or ciliary injection in the region of the involved area.

Conjunctival and ciliary injection may indicate a focal reaction in choroidal lesions. Greyish spots at different levels in the substance of the cornea mav also indicate a focal reaction. A case of leftsided neuro-retinitis, not unlike that associated with albuminuria, and another of right-sided optic neuritis, were shown to be of tuberculous origin by the fact that after the subcutaneous injection of $2.5 \mathrm{mg}$. and $4 \mathrm{mg}$. O.T., vision was reduced from 20/20 to 20/200 in the one case, and from $20 / 40$ to $20 / 100$ in the other. Subsequent treatment by T.R. resulted in complete recovery in each instance.

Curiously enough, it is in tuberculosis of the cornea that definite injury has been done by tuberculin, and in tuberculosis of the choroid and retina no great danger from its use is to be apprehended.

It must be remembered that the focal reaction may be absent from diseases which are definitely tuberculous, even when doses of 10 mg. of tuberculin have been administered. In many cases the diagnosis will depend upon the therapeutic test.

In phlyctenular conjunctivitis and keratitis the writer has tried tuberculin treatment, and found it wanting. He has greater faith in removing infective foci, as diseased tonsils and adenoids, and general hygienic and dietetic measures.

He draws attention to the frequency of relapses, and the long interval which must elapse before one is justified in considering tuberculosis of the eye definitely cured. As regards tuberculin, safety in its administration lies in a dose which is far below that which produces untoward symptoms. A feeling of well-being, good appetite, and increasing weight indicate that the patient is getting the proper amount of tuberculin. He strikes a note of warning as to the necessity of standardizing tuberculins, some of the many now on the market having been shown by Rothe and Bierbaum to possess little or no antigenic powers.

J. Jameson Evans. 


\section{III._OPERATIONS}

(Second Notice)

\section{2.-Sclerectomy}

(I) Foroni, Camillo (Genoa).-Sclerectomia ab externo. Arch. für Ophthal., Vol. LXXXIX Second Number, February, I 9 I 5, p. 393.

(2) Fage, A. (Amiens).-The prognosis and treatment of hydrophthalmos. (Le prognostic et le traitement de. l'hydrophtalmie.) Arch.d'Ophtal., March-April, I9I 5.

(3) Parker, Walter R. (Detroit). - The sclero-corneal trephining operation for glaucoma. A clinical report of 45 operations. Ann. of Ophthal., Vol. XXV, p. 467.

(4) Parker, Ralph H. (Les Moines).-Results of the Col. Elliot trephine operation for glaucoma. Read before the Section on Ophthalmology, Otology, and Laryngology, Sixty-fourth Session, Iowa State Medical Society, Waterloo, May I 2th to 14th, I9I 5. Jl. of the Iowa State Med. Soc., March, I9I6.

(5) Fox, L. Webster (Philadelphia).-The results obtained by the Fox modification of the Elliot operation for glaucoma. Jl. of Ophthal., Otology, and Laryngology, May, 1916.

(6) Trantas, A. (Constantinople). - A new procedure for pre-iridic sclerectomy in glaucoma. (Nouveau procédé de sclérectomie préirienne contre le glaucome.) La Clinique Ophtal., September, I916.

(7) Bistis, Jean.-On Elliot's operative procedure. (Sur le procédé d'Elliot.) Arch. d'Ophtal., Sept.-Oct., I9I6.

(8) Cilleruelo (Valladolid).-Criticism of a new procedure in sclerecto-iridectomy for glaucoma. (Critica a un nuevo procedimiento de iridectoesclerotomia antiglaucomatosa.) España Oftalmológica, October, 1916.

(9) Broder, Chas. B. (New York).-Late infection following the corneo-scleral trephine operation. Med. Rec., October 2 I, IgI6.

(1) "Sclerectomia ab externo" is a modification of Lagrange's sclerectomy for glaucoma, which $\mathbf{C}$. Foroni claims to have devised before he was aware of other modifications introduced by various authors. It is based on the principle emphasized by Lagrange.

The technique is as follows. - A few drops of novocain-adrenalin 
are injected under the bulbar conjunctiva in the immediate neighbourhood of the upper corneal limbus, and the injected area
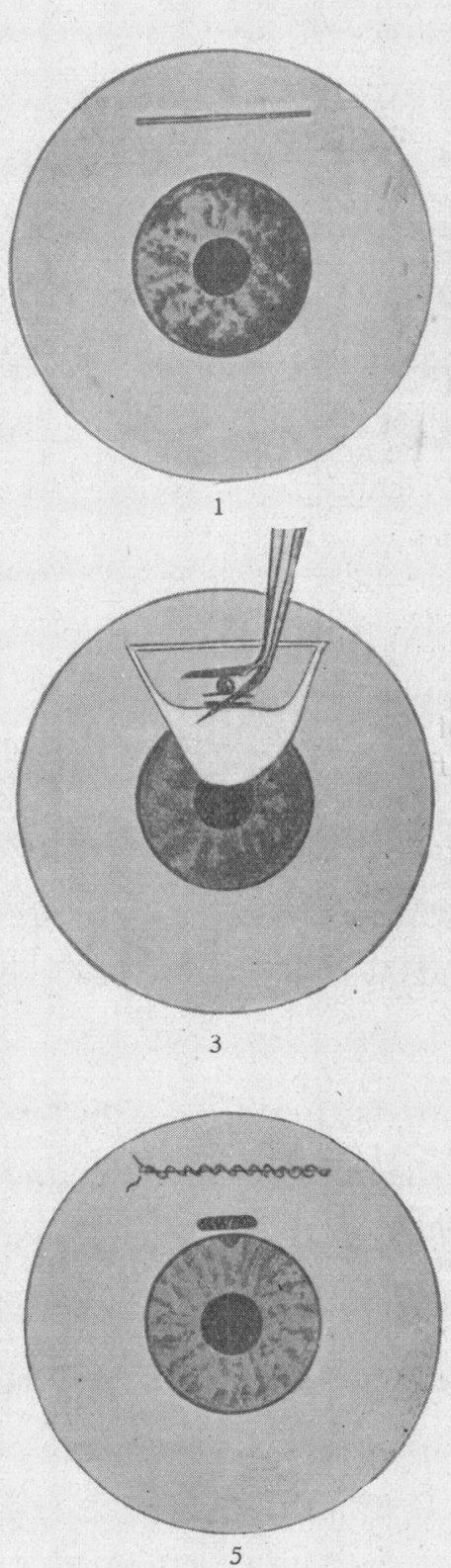
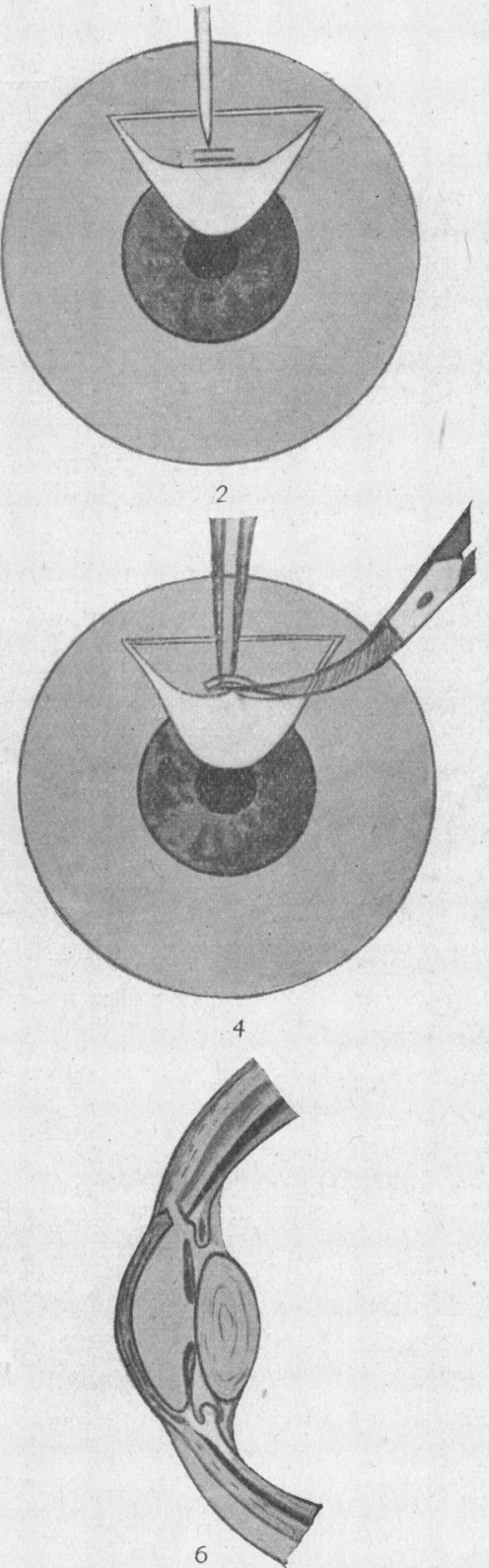

is lightly massaged for a few moments until anæsthesia sets in. After getting the lid-speculum into position, the conjunctiva 
is pinched up with fine-toothed forceps somewhat more than $1.5 \mathrm{~cm}$. above and to one side of the limbus. The Graefe knife is next introduced into the conjunctiva in the horizontal direction, with the cutting edge directed forwards. With the back of the knife gliding on the sclera, an incision from within outwards is made in such a manner that it defines a flap-like piece of tissue composed of conjunctiva and episclera, about $2.5 \mathrm{~cm}$. long and rather more than $1 \mathrm{~cm}$. high (Fig. 1).

This flap is undermined with the point of the Graefe knife carefully down to the corneal margin, and with the edge away from the corneal margin, the knife is passed on the flat side under the flap held upwards, to make sure that the undermining is complete. With care, button-holing of the flap is avoided. The sclera and the corneal margin being freed, the flap is turned down and stretched over the cornea, as far forward as possible. In the sclero-corneal region, and parallel to the limbus, an incision, about $5 \mathrm{~mm}$. long, is made with the point of the knife held at right angles to the surface to be incised. In the same manner, just above and parallel to the first, a second similar incision is made. These two incisions define a rectangular or spindle-shaped piece of sclera, hardly $1 \mathrm{~mm}$. broad.

With the cystotome or the point of the Graefe knife introduced through the second incision, a very fine opening is made into the anterior chamber (Fig. 2). The small peripheral portion of the iris, which bulges immediately into this opening, is either simply incised, or entirely removed with de Wecker's iridectomy scissors (Fig. 3).

Then, the isolated strip of sclera is freed by passing the point of the knife from side to side in the two incisions, next seized with forceps, raised, and completely excised (Fig. 4).

At this stage the conjunctival flap is replaced and the globe massaged with the spatula over the scleral defect, so as to stretch the upper half of the iris and allow the pupil to resume its normal shape. Lastly, the conjunctival incision is closed with a continuous suture (Fig. 5), which is preferable to the interrupted suture, because it is less irritating and not inclined to delay or to prevent union of the lips of the wound. Foroni emphasises the necessity of great care and exactness in the suturing, which is done with black silk, armed with needles of the kind used by Kalt to suture the cornea after cataract operation.

The stitch is removed on the seventh or eighth day, i.e., as soon as the lips are fully united. The removal of the suture is best accomplished by cutting the knot at either end, and exerting a pull at one end.

Foroni claims for his operation the following advantages over Lagrange's sclerectomy and Elliot's operation.-Besides presenting 
all the dangers and difficulties of the incision with the Graefe knife in the classical iridectomy for glaucoma, Lagrange's operation offers the further dangers and difficulties of preparing the segment of sclera to be excised, the excision of which is further complicated because of the peculiar beak-like form of the segment required to be cut out.

In "sclerectomia ab externo," the preparation and excision of the scleral segment and the peripheral or complete iridectomy takes place without any obscuration whatever of the field of operation and with the greatest freedom from disturbance to operator and patient, so that one can control the shape and size of the segment in the desired manner. Thus, in this operation there is no critical moment in the real sense of the term.

As against Elliot's trephining the following points are advanced in favour of Foroni's operation. - The procedure produces a regular fissure instead of a circular opening in the sclera. Because of its long and narrow shape the fissure permits of the iris being dealt with when necessary. Further, it offers a much larger area for the desired filtration, an area which corresponds to the obliterated iris-angle. On account of its form, the opening made by the trephine reaches far too much into the ciliary region. In addition, the opening is too confined in the direction of the irido-scleral ring, where the greatest effect should be attained. The necessity of trephining a second time, to which the adherents of Elliot are driven, is attributed to the shape of the opening and the consequent insufficient filtration. Foroni thinks that what led Elliot and others to suggest the making of two trephine holes instead of one is also to be attributed to the unfavourable round form of the opening.

According to Foroni's method, the reduction of tension is said to occur forthwith, and to be permanent. In no case was there an early or late infection and never in any instance even the faintest striate keratitis noted. To prove these claims, Foroni intends soon to publish his cases, as also to offer an explanation of the mechanism of filtration in his operation.

(2) Fage finds that, from the operative point of view, all authors who have written on this subject during the past thirty years seem agreed on two points, namely, that in hydrophthalmos operation must be early, and that a small incision is necessary.

He has statistics of 30 cases of his own, of which some have not been followed, or have been treated only by miotics. Fourteen have been treated by a modified sclerotomy, i.e., by puncture and counter-puncture without completing the section, and of these, the cases which have been operated on early, have been favourably influenced, whilst five eyes have ceased to increase in size, their tension having been reduced to normal. 
The author's own views as regards operation are as follows:-

Iridectomy should rarely be performed, as it is in this condition a dangerous procedure. Sclerotomy has the advantage of being a short operation, which can easily be repeated if necessary. Sclerectomy must be given an important place, indeed, the most important place, for it is, Fage thinks, the operation which is the most likely to achieve permanent fistulisation of the eye. The method most favoured by Fage is that of Holth, with or without a peripheral buttonhole iridectomy, but he considers Elliot's method offers definite advantages by reason of its simplicity, the small opening involved, and the fact that it can be repeated, if necessary.

\section{BERNARD CRIDLAND.}

(3) W. R. Parker has long interested himself in the subject of sclero-corneal trephining from the statistical point of view, and has contributed careful articles on the subject.

In this communication he presents a methodical analysis of the results obtained in his own cases. He adopts the Elliot technique in its entirety, and lays stress on the thick-based conjunctival flap, which he considers "is a decided factor in preventing the vesicular type of filtration scar, and greatly diminishes the risk of late infection." $\mathrm{He}$ has met with no case of late infection, although in one eye the conjunctiva is now worn through, the chamber is empty, and he has fears for the future. This would seem to be a case for a sliding flap operation. Amongst other complications mentioned are intra-ocular hæmorrhage and loss of vitreous. In two cases of buphthalmos the operation failed, vitreous was lost in both; and he thinks it possible that the site of the operation was too far back. In two chronic inflammatory cases there was ectasia of the iris, and the eye remained painful and irritable. In one case of quiet iritis the pupil became occluded, and the vision fell to light perception. Parker lays stress on the influence of the stage of the disease on the result. In so doing, he is but emphasizing the lesson taught by von Graefe, that the later the operation, the worse the prognosis. He adds :-

"It must be borne in mind that many of the cases here recorded were unfavourable for any operative procedure. In a few cases of absolute glaucoma, in which formerly an enucleation would have been performed, the eyes were made quiet and comfortable by the trephine operation, and I believe one of its best uses is in this type of the disease."

He strongly advocates the inclusion of a complete iridectomy in every case, to avoid trouble with the iris.

In Parker's opinion, the sclero-corneal trephine operation finds its strongest indication in the simple cases of the disease. $\mathrm{He}$ believes that it offers " a method of procedure that is to take a permanent place in the treatment of glaucoma. I cannot but feel, 
however, that no one method of procedure is applicable to all forms of glaucoma, and I doubt very much if the deep iridectomy of von Graefe is to be superseded in cases of acute and possibly subacute cases, where it has so long reigned supreme. Nor am I entirely convinced that in simple cases, if seen early, in which miotics have failed, it is not better to do a deep iridectomy, reserving the trephine operation for those cases in which the iridectomy has failed. To this group I would add all the cases of every type in which an iridectomy is contraindicated."

R. H. Elliot.

(4) R. H. Parker circularized the ophthalmic surgeons of the State of Iowa, to enquire their experience with the Elliot trephine method, and records the results of his enquiries. He lays stress on the fact that his correspondents are men of comparatively small operative practice, and considers that this is a good argument in favour of the continuance of the procedure. Dr. L. W. Dean, in the discussion of the paper, gave the results of his own 25 cases of trephining, and furnished much interesting comment on various technical details. He drew attention to the early fatigue of the retina under the stimulation of bright light, which is so often seen in glaucoma patients, even after successful relief of tension, and commented on this feature of the cases, which is doubtless well known to a large number of ophthalmologists, but which has comparatively seldom been drawn attention to in print. He says: "So far, we have been very well satisfied with our results of trephining in chronic simple glaucoma, when the case has not progressed too far." His results in trephining for secondary glaucoma, for hæmorrhagic glaucoma and for buphthalmos, do not appear to have been very satisfactory. As to the difficulties in technique, he writes: "The trephine operation is much more readily taught to my post-graduate students than the performance of a proper glaucoma iridectomy. It seems to me that the performance of a proper iridectomy for glaucoma is one of our most difficult operations."

de Schweinitz said that he did not consider trephining an easy procedure, though "any one possessed of operative skill can approach the operation with confidence." He lays stress on the statement that the relief of intra-ocular pressure does not always carry with it the cure of glaucoma. He is satisfied that the filtration operations are more efficient than iridectomy in the relief of simple glaucoma, but apparently prefers the latter operation in acute cases. He deals with quiet iritis, with the diagnosis of the type of glaucoma, and with the danger of late infection, and concludes: "Comparatively limited as my experience is, I have had admirable results, as doubtless all of us have had (from the Elliot operation), but much as I admire Colonel Elliot's important contributions to the therapeutics of glaucoma, especially from the operative standpoint, I do not 
believe that we should be blind to certain ever present dangers which surround the operation and its results."

R. H. Elliot.

(5) Fox, was deeply impressed at the International Medical Congress of 1913, in London, with the case put forward for the Elliot operation of sclero-corneal trephining, which he had adopted two years earlier, in a modified form, in his own practice.

$\mathrm{He}$ gives the history of the various operations for glaucoma, and concludes with a description of Elliot's method, and of his own modification of it. Unfortunately, he figures the old flap which Elliot abandoned eight years ago. The matter is of some importance, since Fox practically copies the shape of the flap, but dissects it away from the corneal edge and leaves it hinged along its nasal side. It is thus a modified van Lint flap. Fox also prefers the von Hippel mechanical trephine to any hand-driven instrument. " Since 1911," he says, "I have had an exceptionally large number of cases, where I have performed my modification of the Elliot method, and the drainage has been excellent. Vision has been held and the tension reduced to almost normal. . . . I was obliged to repeat the trephine or to perform a secondary sclerectomy in less than 5 per cent. of the cases, which I consider speaks volumes for the Elliot method. In regard to late infection I have been exceptionally fortunate, and I attribute this to the fact that I have guarded against pyorrhœa alveolaris, which I am confident is a contributory cause of infection following operations on the eye."

R. H. Elliot.

(6) Trantas after recounting the various disadvantages of the Lagrange, Elliot, and Holth methods, describes his sclerectome and his operation. The sclerectome is a kind of double-edged Graefe knife, from the cutting edges of which, at a certain distance along the blade, there are two wing-like projections, the anterior, more or less vertical, edges of which are sharp. A conjunctival flap is dissected down, and turned over the cornea, as in the Elliot procedure, but without the fine toilet required in connection with the subconjunctival tissue in that operation. The Graefe-like edge of the sclerectome is then introduced as if one were about to perform an ordinary iridectomy for glaucoma, except that the incision is shorter. The instrument is pushed on, when the wing-like edges scoop out the required portion of sclera, which latter is removed in the hollow of the blade between the two wings.

The author claims that, in his procedure, what requires three steps and three instruments in other operations, is done in one step and with one instrument.

At the end of the article there is an account of a method of estimating by transillumination the amount of free sclera available 
between the cornea and the ciliary body. This, however, is not new, as it was described by the author in 1898 .

ERNEST THOMSON.

(7) In a brief communication Bistis records his experience of the trephine operation for glaucoma. He has operated eleven times, in ten instances for chronic primary glaucoma, in one instance for secondary glaucoma.

Bistis has adopted the method proposed by Dupuy-Dutemps in the formation of the conjunctival flap; he separates the conjunctiva from the margin of the cornea over the upper third of its circumference and exposes a large area of sclera. Two silk stitches are inserted in the incised conjunctiva one on each side of the cornea, and after completion of the trephining, these are tied. Bistis believes that by this method better protection of the trephine aperture is obtained than by the usual conjunctival flap dissected from above downwards. His experience of Elliot's operation, so far, has been encouraging.

J. B. LAWFORD.

(8) Cilleruelo, who is apparently a disciple of Lagrange, takes exception to the statement made by Ruiz, that his new glaucoma operation, of which an account has been published in España Oftalmológica, in April, 1916, and in the Archivos de Oftalmologia in August, 1916, offers a simpler technique than that of Lagrange's classical operation. This criticism is made apparently on theoretical grounds, for it does not appear from a perusal of his article, that Cilleruelo has ever performed the Ruiz operation.

It may be of interest to readers of the BRITISH JOURNAL OF OPHTHALMOLOGY if we give a transcript of the description of the Ruiz operation as copied by Cilleruelo.-Sclerecto-iridectomy of Ruiz.- " Having arranged a speculum, and fixed the eye with Graefe forceps, one dissects with scissors a conjunctival flap superiorly, which is turned forwards, and a section with a broad keratome is made at $1 \mathrm{~mm}$. from the limbus, in the sclerotic denuded of conjunctiva, penetrating into the anterior chamber in front of the iris ; a complete iridectomy is then performed according to the usual technique. With fine dissection forceps, the inferior lip of the scleral wound is raised, and with punch forceps a very narrow piece of the sclerotic is extirpated, and the same manipulation is effected on the upper lip of the scleral wound, thereby making a fistulous orifice similar to that in the Elliot operation: the wound and the fistula are covered with the conjunctival flap, and the operation is finished."

Cilleruelo points out, quite truly, that Lagrange's principles underlie the operation in question, as well as many other operations for the relief of chronic glaucoma, of which he instances the operations of Dor and of Holth, and that Ruiz's method differs really only in technique. He states most decidedly that, in his opinion, the Lagrange technique is the simpler. 
He makes no allusion to the modifications of Lagrange's operation which have been published in this country by Pooley and by David Priestley Smith.

The article is illustrated by reproductions of the punch-forceps of Ruiz and Lagrange.

(9) Broder publishes two cases of late infection following trephining, which he has met with in his practice.

The first patient had been trephined morethan fouryears previously. Three years after the operation, the tension was $22 \mathrm{~mm}$. Hg., the disc slightly cupped, and V. $=20 / 30$. He was apparently doing well, until some aniline pigment fell into his eye, causing ulceration of the cornea and hypopyon, the process being very acute from the first. Under treatment, the eye improved, but V. was reduced to $5 / 200$, on account of opacities in the media. "The intra-ocular inflammation in this case was evidently secondary to the corneal ulcer, the infection involving the conjunctival flap and spreading to the ciliary body through the scleral opening." It must be admitted that the test to which the eye was put was a very severe one; moreover, the history of glaucoma, controlled for more than four years during which the patient was able to go on with his trade, is a tribute to the success of the original operator.

In the second case, the opposite eye had undergone two operations for glaucoma, and had then been enucleated three years previously. Shortly after this, the right eye was successfully trephined. All appears to have gone well until the patient contracted a severe and intractable conjunctivitis, which resulted in iridocyclitis, hypopyon, and great reduction of vision.

This experience has led Broder to advise that miotic treatment should be fully tried until it is obvious that it is failing to control the glaucomatous condition; he would then undertake a broad iridectomy ; if this failed, he would fall back on trephining, making the conjunctival flap as thick and large as possible.

R. H. Elliot.

\section{IV.-REMEDIES}

(Third Notice)

(I) Delorme, A. (Bordeaux). The treatment of purulent gonorrhœal ophthalmia with the vaccine of Nicolle and Blaizot. (Le traitement de l'ophtalmie purulente gonococcique par le vaccin de Nicolle et Blaizot.) Arch.d'Ophtal., March-A pril, I9I6.

(2) Simon de Guilleuma, J. M. (Barcelona).-Iodine ionization as a treatment for cataract. (L'ion iode comme traitement de la cataracte.) La Clinique Ophtal., October. I9I6. 
(3) McIntosh, James, and Fildes, Paul (London).-The factors which govern the penetration of arsenic(salvarsan)and aniline dyes into the brain and their bearing upon the treatment of cerebral syphilis. Brain, October, 1916.

(4) Lawford, J. B. (London).-Discussion on the treatment of syphilitic eye affections by the newer methods. Trans. Ophthal. Soc. U.K., Vol. XXXVI (1916), p. Io.

(5) Browning, S. H. (London). Ibidem, p. 29.

(6) Harrison, Lieut.-Col. (R.A.M.C.). Ibidem, p. 35.

(7) Lane, J. Ernest (London). Ibidem, p. 42.

(8) Lawson, Arnold (London). Ibidem, p. 46.

(g) Griffith, A. Hill (Manchester). Ibidem, p. 49.

(IO) Cross, F. R. (Bristol). Ibidem, p. 50.

(I I) Clegg, J. Gray (Manchester). Ibidem, p. 53.

(12) Berry, Sir George (Edinburgh). Ibidem, p. 54.

(13) Whitehead, A. L. (Leeds). Ibidem, p. 55.

(14) Mackay, George (Edinburgh). Ibidem, p. 57.

(I5) Bickerton, T. H. (Liverpool). Ibidem, p. 58.

(16) Bunch, -J. L. (London).-Salvarsan and its substitutes. Practitioner, March, 1917.

(I7) Jenkins, C. E. (London).-A simplified technique for the administration of neo-salvarsan. Ibidem, p. 287.

(18) Vassallo, S. (Leeward Islands).-Cases with comments. Two cases of sudden death after kharsivan injection. Ibidem, p. 290.

(1) Delorme records eight cases of gonorrhoal ophthalmia treated by vaccine prepared as described by Nicolle and Blaizot, two of which had been shown by Lagrange at the Bordeaux Medical Society. The results were very striking, as after a maximum of five injections, five of the cases, in spite of the presence of early corneal lesions, were completely cured. In one case, after four injections, a relapse occurred three days later, but four more injections effected a complete cure. In one case of a boy of seventeen, in spite of seven daily injections, only slight improvement was noted. In this case treatment by steam was successful. The only failure was in a debilitated woman of seventy-four, who was mentally deranged and refused food.

An account of the method of preparation of the vaccine is to be found in the original paper by Nicolle and Blaizot in the Comptes Rendus, 1913, p. 1009, and, as this is probably inaccessible to the majority of our readers, we quote from it here. 
As the authors found that a pure gonococcal vaccine was too toxic for use, they endeavoured to discover some method of reducing its virulence. In the course of their investigations they found that another coccus, which they named the synococcus, frequently accompanied the gonococcus. The synococcus differed from the gonococcus in its rapid growth on media without serum, the production of an orange pigment, and in being Gram-positive. This coccus forms a part of their vaccine, the method of preparation of which is as follows.-A pure gonococcus, which has been induced to grow on a medium relatively poor in serum, and also a synococcus, are inoculated on separate tubes of a medium consisting of meat broth, 100 ; urea, 0.4 ; glucose, 2 ; phosphate of ammonia, 0.05 ; sea salt, 1 ; agar, 1.5 ; to which is added in the tubes 0.5 c.c. of rabbit's serum to each 5 c.c. The synococcus tube receives no serum. The cultures are removed from the incubator after 24 hours, emulsioned in 0.7 per cent. solution of fluoride of sodium, washed and centrifuged. The vaccine is made of nine parts of synococcus culture to one part of gonococcus, and titrated to contain 500 million microbes per c.c. The vaccine is kept for 48 hours in the ice chest to destroy the vitality of the organisms. Dose, 0.5 c.c. diluted with 1 c.c. of normal salt solution and given intramuscularly. The synococcus culture alone was found to be non-toxic in much higher doses.

E. E. H.

(2) Simon de Guilleuma after referring in a general way to the use of the iodides in the treatment of cataract, whether in the form of collyria or of ointments, relates one case in which he employed ionization. The solution was 1 per cent. sodium iodide, the current 1 milliampère, and the time 5 minutes. The author seems satisfied that he caused the progress of the cataract to cease ; but it must be admitted that the case is not very convincing.

\section{ERNEST THOMSON.}

(3) McIntosh and Fildes in a previous paper (Proc. Roy. Soc., B. 1914, Vol. LXXXVIII, p. 320) have shown that no arsenic can be found in the substance of the brain after the intravenous injection of salvarsan or neo-salvarsan. Further, that this is not due to any lack of affinity between the brain-cells and the drug, but to an obstruction to the passage of the medicament from the blood-stream into the brain substance.

In the present communication they detail experiments upon rabbits designed to throw light upon the factors involved in penetration or non-penetration. Briefly, various dyes were selected for this purpose. A rabbit was injected intravenously with a large dose of an aniline dye and killed five minutes later by the injection of 10 c.c. of air into the ear vein. The distribution of the stain in the tissues was then noted, and the brain and cord were next examined. The 
cerebro-spinal fluid was obtained free from blood by exposing the cord, and puncturing the membranes with a capillary pipette. As examined by the method of intravenous injection, stains may be divided into two groups, as follows:-1. Those which colour the tissues generally and also the central nervous system; and 2. those which colour the tissues generally, but not the central nervous system. Among the former are included methylene blue, neutral red, alizarin biue, and malachite green, and among the latter fluorescine, indigocarmine, acid fuchsin, light green, trypan red, trypan blue and pyrrhol blue. Seven experiments are described in some detail, but it will suffice if we give the conclusions reached by the authors. They are as follows :-(1) Certain dye substances can pass directly from the blood to the brain substance proper without being found in the cerebro-spinal fluid, while others fail to penetrate into the brain. (2) The chief factor which governs the passage of the dyes is their solubility reactions. (3) This is a peculiar solubility and not a general lipoid solubility. (4) It corresponds to a solubility in chloroform and in water or perhaps to their partition co-efficient in these liquids. (5) The present day arsenical remedies are to some extent inefficient in the treatment of syphilis of the central nervous system because they do not possess the necessary solubility to allow them to pass from the blood-vessels into the brain substance. Their relative inefficiency bears no relationship to their absence from the cerebro-spinal fluid.

S. S.

(4) Lawford discusses the treatment of syphilitic affections of the eye by the newer methods from a purely clinical standpoint. Although not wide, his experience of the "newer methods" has helped him to form some more or less defined opinions.

In the first place, he summarizes the discoveries that led to the present advance: (1) by Metchnikoff and Roux in 1903 that a chimpanzee could be inoculated with the virus of syphilis; (2) by Schaudinn and Hoffmann in 1905 of the Spirochata pallida; (3) of Wassermann's discovery in 1900; and (4) lastly, of Erhrlich and Hata's " 606 " in 1909. He then passes on to consider the organic arsenic compounds, where the arsenic is in direct combination with a carbon atom. Of these compounds there are two main groups: (1) those obtained from the aliphatic or fatty series, the use of which in syphilis is now practically abandoned; and (2) the aromatic or benzol-ring compounds, including atoxyl, arsacetin, hectine, salvarsan, etc. Many cases of blindness from the administration of atoxyl in sleeping sickness have occurred, and a similar result has followed its employment in cases of ocular syphilis. Lesions of the optic nerve have also been recorded after the administration of arsacetine, orsudan, hectine, and indarsol (the last-named in cats and rabbits). 
There is general agreement as to the efficacy of salvarsan in the acute iritis of secondary syphilis, in gummatous cyclitis, and in the early exudative stage of choroiditis. Lawford gives brief details of four cases of syphilitic iritis where a rapid and good result followed the intra-venous injection of salvarsan (or neo-salvarsan). In only one case was more than a single injection employed.

In oculo-motor paralysis, judged by published records, the results of salvarsan treatment resemble those obtained by the older remedies in their uncertainty. In a tabetic paresis of one external rectus mentioned by the author, two intra-venous injections of neo-salvarsan, at an interval of fifty-one days, did not lead to complete recovery. In cycloplegia and iridoplegia of syphilitic origin salvarsan was worthy of trial. Lawford has found records of the loss of light-reflex of the pupil successfully treated by salvarsan (Zahn, Marie, Tissier, Michaelis, and Dor), although the only case treated by himself was not successful.

As to the influence of the newer remedies in primary atrophy of the optic nerve, Lawford has had no personal experience. $\mathrm{He}$ found no reliable evidence from their employment. He has seen the "lightning pains" of the commonly associated tabes markedly relieved by salvarsan.

In five cases of interstitial keratitis of congenital syphilis treated by the newer methods, Lawford had no result in two; in one, definite though slight improvement in three weeks ; in one, vision rose from $3 / 60$ to $6 / 24$ after three injections; in one case there was slight improvement after four injections, spread over a period of six weeks, but this was followed by a severe recurrence two months later. He concludes that "we cannot reasonably expect any marked or rapid change in the corneal condition from the internal administration of anti-syphilitic remedies." The local application of salvarsan or salvarsanised serum is not spoken highly of. Lastly, he points out that single doses of salvarsan in interstitial keratitis are of no value. The treatment should consist of a course of injections at intervals of two or three weeks.

As to the disastrous after-effects of salvarsan, especially lesions of the cranial nerves, Lawford expresses the view that they are more likely to follow the administration of single large doses than of repeated small injections. His personal experience of untoward results from salvarsan has been limited to two cases, one where acute delusional insanity came on three days after treatment, and another of interstitial keratitis, mentioned above, where a severe recurrence followed two months after the last injection.

Finally, Lawford places on record his opinion that the administration of salvarsan and its allies should always be associated with or followed by the older remedies, mercury and iodine.

(5) The communication by Browning contains little about 
the treatment of eye affections, although much about the newer remedies, as salvarsan, neo-salvarsan, kharsivan, neo-kharsivan, arsenobenzol, novarsenobenzol, and luargol. $\mathrm{He}$ urges the necessity of scientific diagnosis, where full use is made of both clinical and laboratory methods. He regards the Wassermann method, as originally carried out, as "by far the most reliable for general use." There is little doubt that the value of the newer preparations has been overrated in the past, and it is now recognized that these arsenical compounds must be combined with mercury to bring about a cure. No routine can be followed; every case must be treated on its merits. The question of cure rests upon the Wassermann reaction. To give mercury by the mouth is probably the worst way of administering that remedy: injection is the method that meets the case most efficiently. It cannot be doubted, however, that inunction is one of the best methods of getting a patient quickly under the influence of mercury.

Eye syphilis cannot be treated apart from general syphilis, and Browning has "seldom seen a case of eye syphilis properly treated." Such a patient should be placed under the care of an expert syphilologist, and he should not be pronounced cured until proved so by repeated Wassermann reactions of blood or cerebro-spinal fluid, or by any other tests that may be considered necessary.

Browning details the precautions as regards preparation of the patient that should be taken before the injection of any of the preparations of arsenic. Absolute contra-indications are far from common. Among the complications of all the injections he enumerates phlebitis or thrombosis of the vein selected for the operation; general symptoms during the injection, as sickness, faintness, or collapse ; or several hours later, as headache, rigors, vomiting, or diarrhœa; or, later still, as jaundice and certain cutaneous troubles. Browning has given nearly 10,000 doses of these arsenical preparations without witnessing nerve complications as a result.

He has seen at least five cases in which interstitial trouble developed in the second eye during an intensive course of treatment with salvarsan or one of its derivatives.

He does not recommend either intramine or ferrivine.

$\mathrm{He}$ notes that "606" does not have any effect upon the Wassermann reaction in interstitial keratitis. In these cases treatment by intensive mercurial inunction is much better.

(6) Lieut.-Col. Harrison, who directs his remarks in the main to the general treatment of syphilis, states that despite a large experience, he has been unable to discover any difference in the therapeutic effects of kharsivan and arseno-benzol, and salvarsan. He lays it down that no programme of anti-syphilitic treatment is complete unless it includes one of the newer arsenical compounds. 
Considerable attention has been paid to the question of a commencing course of salvarsan (or of its substitutes) and mercury. The idea is to find the most economical method of using salvarsan. Originally, in conjunction with Colonel Gibbard, he advocated three full doses of salvarsan and ten injections of mercury, lasting ten weeks, but about thirty serological relapses occurred in the year. $\mathrm{He}$ is inclined to the minimum course advocated by Gennerich, but his mind is evidently not made up fully on the subject. The necessity of further treatment should be determined by regular examinations of the blood and cerebro-spinal fluid, which should be kept up for at least two years.

(7) Lane has given up the use of kharsivan, neo-kharsivan, and nov-arseno-benzol, on account of their toxic properties. $\mathrm{He}$ has found galyl thoroughly satisfactory, and his present practice is to give four intra-venous injections of galyl at weekly intervals, and to follow these by eight to twelve injections of calomel or grey oil, and after an interval of three months, to have a Wassermann made. Everything depends on commencing the treatment immediately the diagnosis of syphilis is made. Intramine is not to be compared, in Lane's opinion, with salvarsan or with galyl. Ferrivine has been employed in one patient, and general symptoms at once followed its use. Luargol, a French remedy, is spoken of as quite the last word in the treatment of syphilis. It is said to be followed by only slight reaction, to be very rapid in its effects, and to be less toxic than the other substitutes for salvarsan.

(8) Lawson has obtained good results from " 606 " in cases of interstitial keratitis that are of syphilitic origin, pure and simple. But where tubercle exists as a factor the remedy is of little, if any, benefit. Marked debility in a case of interstitial keratitis is suggestive of tubercle. In his experience, when tubercle is combined with syphilis, salvarsan is apt to cause positive harm. When the two infections coincide, tuberculin may prove to be the more successful method of treatment.

(9) Griffith mentions a case of disseminated pigmented choroiditis in which the sight rose from J. 16 to J. 1 after one injection of salvarsan and a fortnight's mercurial inunction.

(10) Cross has seen cases of acute iritis clear up wonderfully after a single injection of salvarsan, and speaks highly of the value of small doses of neo-salvarsan in the treatment of interstitial keratitis.

(11) Clegg has had experience with salvarsan, neo-salvarsan, and galyl. He has treated by those remedies 59 cases of various types of ocular syphilis, and of 44 which he traced, 27 showed distinct improvement. As to interstitial keratitis, his experience has not been very satisfactory.

(12) Sir George Berry has never believed in or practised anti- 
syphilitic treatment of interstitial keratitis. In certain cases he has been obliged to resort to treatment by tuberculin.

(13) Whitehead had a fatal result after two injections of galyl. The patient, a middle-aged woman suffering from chronic syphilitic iritis, died eight weeks after the first injection, with symptoms of dermatitis, enteritis, and wasting. In cases of interstitial keratitis (with a positive Wassermann reaction) he gave three injections of salvarsan at intervals of a fortnight, followed. by mercurial inunction and large doses of the syrup of iodide of iron. In four cases the second eye was affected either during or after a course of injections.

(14) Mackay dwells upon the importance of mixed infections, and agrees with Lawson (No. 8) in thinking that some of the disappointments from treating interstitial keratitis with antisyphilitic remedies were due to this cause. He mentions a case where vision, much reduced by vitreous opacities, was brought to $6 / 9$ and J. 1 after a couple of intra-muscular injections of salvarsan. The man, however, died of general paralysis of the insane.

(15) Bickerton alludes to the case of a woman with optic neuritis, diplopia, headache, and nausea, who presented a negative Wassermann reaction. A colleague considered the case to be syphilitic, and gave five injections of galyl, along with mercury and potassium iodide. Optic atrophy supervened, and the patient now possesses perception of light only. The case is presumed to be one of intra-cranial gumma. Bickerton thinks a decompression operation might have been done with advantage.

S. S.

(16) According to Bunch, the English substitute for salvarsan is kharsivan, and there is also a more soluble compound corresponding to neo-salvarsan, called neo-kharsivan. Other "approved" substitutes are arsenobillon and novarsenobillon. Bunch gives several injections of neo-kharsivan dissolved in saline solution at intervals of a week or ten days, and alternates these injections with intramuscular injections of grey oil, corresponding to 6 to 7 centigrammes of mercury for each dose. Of intramine and ferrivine he does not speak in high terms. He finds that the Wassermann reaction is usually negative after two injections of 0.3 gramme of the French preparation galyl, followed by four more doses of 0.25 gramme given at weekly intervals. Hectine has been largely employed by Gaucher and other Paris dermatologists. It should be supplemented by intra-muscular injections of mercurial oil. Luargol, or "102," is the latest anti-syphilitic remedy. Dissolved in a solution of sodium hydrate, it forms a dark-brown solution. It contains silver, bromine, antimony, and 20.70 per cent. of arsenic. One tenth of a gramme is the initial dose recommended in the treatment of syphilis in females. Luargol has been shown 
to be very powerful in sleeping sickness, as well as in other forms of trypanosomiasis.

S. S.

(17) The plan recommended by Jenkins is as follows.- The patient is put to bed for 24 hours, castor oil is administered overnight, and no food is allowed for at least four hours before injection. Fifty c.c. of sterile saline solution (preferably made with distilled water) are poured into a sterile medicine glass, and a glass syringe, capacity about 15 c.c., is filled with the liquid. The neosalvarsan is placed in a second medicine glass, into which the contents of the syringe are expelled. Solution usually occurs readily. This solution, which should be of a clear yellow colour, is drawn up into the syringe, air bubbles are expelled, and the needle is detached. The skin of the patient's arm is sterilized by means of iodine, and the needle is passed into the largest vein on the front of the elbow joint. When the needle is correctly placed, a trickle of blood appears from its orifice; the filled syringe is attached to the needle, and the injection is slowly made. The piston should be moved at a rate not much faster than the second hand of a watch, which means that the time taken to give the injection is about ninety seconds. A firm bandage is applied, and the patient is kept in bed for the remainder of the day.

S. S.

(18) Vassallo reports two deaths in lads a few minutes after the intra-gluteal injection of $0.3 \mathrm{gm}$. of kharsivan. Autopsy gave no clue to cause. Shock is suggested by the author. It may be noted that the post-mortem appearances were not inconsistent with such a view.

S. S.

\section{NOTES}

American Psyche American Psychological Society has Society

appointed thirteen committees to deal with "relations of psychological methods and information to military activities." The President is Professor Robert M. Yerkes, whose elaborate experiments with the Japanese dancing mouse are familiar to students of the physiology of vision. One of the committees is engaged upon visual problems of military importance. Its president is Professor Raymond Dodge, who in 1898, in conjunction with Professor Erdmann, published a book on Reading. This book records the most exhaustive series of experiments on the physiology and psychology of reading which has yet been performed. It must be regarded as the authoritative 